\title{
Práticas de leitura: relações entre língua, texto e discurso
}

\author{
Agostinho Potenciano de Souza * \\ Luana Alves Luterman **
}

\begin{abstract}
Resumo
Buscamos contribuir para a formação de professores de Língua Portuguesa, indagando sobre as práticas de estágio e sua correlação com o que é estabelecido como características desse ofício. Para conhecermos o bem a que nos propomos, pesquisamos o histórico da disciplina (SOARES, 2002; RAZZINI, 2001) que se configura em nova formação discursiva (FOUCAULT, 2005) na linha das práticas de leitura e escrita, contrariando a formação anterior, voltada para o domínio da língua padrão. A partir de observações de estágios e dos relatórios daí gerados, constatamos que as práticas de ensino de Língua Portuguesa ainda estão distantes do que é proposto oficialmente.
\end{abstract}

Palavras-chave: Língua Portuguesa. Ensino. Estágio. Formação de professores. Leitura.

\section{Reading practice: relations between language, text and discourse}

\section{Abstract}

We seek to contribute to the training of Portuguese Language teachers, inquiring about training practices and its correlation with what is established as characteristics of this craft. To know the good we set ourselves, we researched the history of the discipline (SOARES, 2002; RAZZINI, 2001) that is configured in new discursive formation (FOUCAULT, 2005) in line with the practices of reading and writing, contrary to the previous, focused training to the default language of the area. From observations of stages and reports generated there, we found that the Portuguese Language teaching practices are still far from what is proposed officially.

Keywords: Portuguese. Teaching. Internship. Teacher training. Reading.

\author{
O poema \\ pena um caminho errante, como estrela \\ que vai nascer no céu, certa, esperada. \\ Heleno Godoy
}

\footnotetext{
* Professor da Faculdade de Letras/UFG. Doutor em Estudos Linguísticos pela Universidade Federal de Minas Gerais. E-mail: apotenciano@uol.com.br

** Professora da Universidade Estadual de Goiás - UEG, Câmpus Inhumas. Doutora em Letras e Linguística pela Universidade Federal de Goiás. E-mail: luanaluterman@yahoo.com.br
} 


\section{Qual é o bem?}

Abrir-se a indagações sobre alguma ação que fazemos, além de ser a procura de racionalidade sobre o fazer humano, dá ao investigador uma procura de finalidade dessa ação perscrutada, vista como um bem:

Toda arte e toda indagação, assim como toda ação e todo propósito, visam a algum bem; por isso foi dito acertadamente que o bem é aquilo a que todas as coisas visam. [...] Mas como há muitas atividades, artes e ciências, suas finalidades também são muitas; a finalidade da medicina é a saúde, a da construção naval é a nau, a da estratégia é a vitória, a da economia é a riqueza. (ARISTÓTELES, 1996, p. 118)

Neste artigo o bem que procuramos possui duas partes correlacionadas: o conteúdo do ensino da Língua Portuguesa e como formar professores de Língua Portuguesa. O percurso da nossa indagação pretende compreender a finalidade desse bem, um conceito que insiste no caminho da vida como o cuco que acusa as horas de um relógio, porém, pouco definido anteriormente às ações. Se a finalidade era vista com olhos turvos antes da ação, após esta reflexão, procura-se a difícil clareza quanto a esse bem, embora não passe de uma tentativa de acertar o alvo:

Não terá uma grande influência sobre a vida o conhecimento deste bem? Não deveremos como arqueiros que visam a um alvo, ter maiores probabilidades de atingir assim o que nos é mais conveniente? Sendo assim, cumpre-nos tentar determinar, mesmo sumariamente o que é este bem, e de que ciências ou atividades ele é o objeto. (ARISTÓTELES, 1996, p. 118)

Embora o argumento que Aristóteles encaminha seja para apresentar a ciência política, "que determina quais são as demais ciências que devem ser estudadas em uma cidade", apropriamo-nos dele para afirmar uma ética quanto ao ensino da Língua Portuguesa, uma dessas ciências, no caso de nossa pólis. Procuramos determinar, mesmo sumariamente, o que é este bem, como foi determinado pela formação sócio-histórica, como está sendo executado nas milhares de salas em que acontece a aula de Português. Sobretudo, olharemos como espectadores, afastando-nos um pouco do espaço de luta, para melhor entender o bem.

Na obra referida, o filósofo grego admite que os bens, tanto quanto as ações políticas, "parecem igualmente vagos". Porém, o bem, qualquer que ele seja, é a felicidade. Quanto a essa, a pólis a entende de modo diferente, de acordo com a vida 
dos seus homens: a "maioria, e os mais vulgares entre eles, parecem (não sem algum fundamento) identificar o bem, ou a felicidade, com o prazer." (IDEM, p. 121); um segundo grupo, "as pessoas mais qualificadas e atuantes identificam a felicidade com as honrarias, pois pode-se dizer que estas são objetivo da vida política." (IDEM, p. 121); o terceiro tipo de vida é o dos que acham a felicidade na vida contemplativa, conceito retomado de Pitágoras que, vendo os grandes jogos gregos, identificou ali três tipos de homens: os negociantes, os competidores e os espectadores e fez disso a metáfora da expressão teoretikós bios literalmente, "vida do espectador", vida contemplativa. (Cf. nota 3 em ARISTÓTELES, 1996, p. 123). Esta é a vida do filósofo: olhar, contemplar, indagar, buscar respostas.

Essas ponderações podem ajudar a pensar uma filosofia do nosso tema, colocando-nos no terceiro grupo, procurando razões que forneçam os fundamentos para o discernimento quanto ao nosso bem e nos conduzam a deliberações que favoreçam o valor moral e intelectual do nosso agir, o que caracteriza e dá forma ao nosso ofício. Para isso, é melhor um olhar afastado dos negociantes (políticos, empresas, mídia), colocando-nos no lugar dos teóricos, aqueles que observam, examinam, especulam sobre o que veem: o fazer dos lutadores, tão presos à ação, que não se distanciam dela para examiná-la de longe, embora possam fazer isso também.

A história política desse ensino mostra determinações que modificam o alvo desse bem. Desde o surgimento da disciplina, no tempo do Império, até meados da década de 1980, o bem predominante era o domínio da língua padrão, ou seja, professores, material didático, alunos, todos estavam empenhados em adquirir a norma culta da língua. Nas últimas três décadas, pesquisas das universidades têm provocado uma virada conceitual sobre esse bem: ensinar a Língua Portuguesa é proporcionar condição de acesso dos alunos aos bens produzidos pela língua: textos e discursos em circulação no mundo social. É o abandono dos estudos da gramática prescritiva?

De novo, o filósofo grego nos alerta:

[...] há um certo alvo a visar, no qual as pessoas que usam a razão fixam o olhar para intensificar ou relaxar os esforços no sentido de adotar o meiotermo; e há um certo padrão determinando o meio-termo, que dizemos situar-se entre o excesso e a falta e ser conforme a razão. (ARISTÓTELES, 1996, p. 216)

Alcançar o meio-termo pode significar que nossas subdivisões de conteúdos devam não ser tratadas com excesso nem com falta. Usar a razão para intensificar ou relaxar esforços tem sido o trabalho acadêmico de artigos, dissertações e teses, bem 
como formulação de um dos principais documentos sobre este bem, os Parâmetros Curriculares Nacionais (PCN), de 1998, que resultaram de muitas horas de trabalho de vários grupos dos professores das universidades brasileiras. Basta ter o livro em mãos e olhar o modo de sua produção. Não que esse documento seja irretocável, mas ali estão as principais razões do meio-termo em relação a diversas práticas de linguagem: escuta de textos orais, leitura de textos escritos, produção de textos orais, produção de textos escritos, análise linguística (BRASIL, 1998).

Ali também está desenhada a finalidade deste bem: "contribuir para garantir a todos os alunos o acesso aos saberes linguísticos necessários para o exercício da cidadania." (BRASIL, 1998, p. 19) Esse é o alvo, uma formação de valor moral e intelectual do cidadão, uma virtude agradável e harmoniosa (valores propostos por Aristóteles aos cidadãos da pólis). A reta razão, por uma procura do meio-termo, evitará a deficiência e o excesso no ensino desses conteúdos da Língua Portuguesa. Caso isso não seja perseguido, ficará improvável atingir o alvo, a finalidade desse bem.

\section{Histórico da disciplina}

Nem sempre a disciplina soube caminhar no meio-termo. Nem sabe. Essa sabedoria sobre o bem ainda não se tornou uma procura generalizada. Tanto no espaço da formação dos professores (as licenciaturas), quanto no espaço da atuação (as aulas de Português em todas as escolas, públicas e particulares, em todas as séries), as práticas de ensino ora se voltam para o ensino gramaticalista, ora fatiam a disciplina por professores separados, e sem contato, um para cada conteúdo, ora executam tarefas propostas pelo livro didático, quase sempre sem outro projeto que não esse, o do livro adotado.

Até meados do século XX, a escola não era para todos - nem foi frequentada pelos escravos no século XIX, nem foi um projeto para as classes populares e rurais até pela década de 1960. Os que tiveram acesso à educação, nessa época, viram a disciplina, hoje denominada Língua Portuguesa ou Português, sob o viés da sua formação durante o Império. Nessa época, a partir de 1837, essa disciplina desenvolve-se como: a) gramática: morfologia, sintaxe, etimologia (filiada à gramática latina); b) retórica: regras para o bem falar e escrever, imitação dos mestres; c) poética: poesia lírica, épica e trágica, leitura de textos de autores clássicos (SOARES, 2002).

O modo didático de condução desses conteúdos era muito próximo ao tradicional dos jesuítas, desde a época do descobrimento: ler, copiar e aprender, repetir sem discutir. Porém, algo novo surge: ler obras exemplares, imitar a língua dos que ficaram 
como clássicos - surgem as antologias escolares, com textos para leitura, algumas sem trabalhos com a gramática, outras com alguns exercícios formais. A mais utilizada por mais de setenta anos foi a Antologia Nacional (1895-1969) de Fausto Barreto e Carlos de Laet, composta por textos de autores clássicos (RAZZINI, 2001).

No final dos anos 1990, o Ministério da Educação e Cultura produziu os PCN (BRASIL, 1998), os quais tornaram-se a referência oficial para o ensino básico e são, hoje, a configuração da disciplina LP e das demais disciplinas. Desse modo, a leitura e a releitura dos PCN tornam-se o principal instrumento do pensar teórico para o fazer do professor de LP. A partir da noção de linguagem como interação entre os falantes, os parâmetros sugerem que cada agrupamento de professores (do estado, de uma regional, do município, de uma escola) defina, a partir dos PCN, como irá fazer seu trabalho em Língua Portuguesa. Os conteúdos devem ser pensados em uma relação de uso e reflexão, de modo que a leitura, a produção oral e escrita e a análise linguística sejam conhecimentos entrelaçados para que o aluno tenha a competência discursiva, que inclui a competência linguística e a estilística, com o objetivo de compreender a cidadania como participação social, "de maneira crítica, responsável e construtiva".

Podemos entender que esse documento chegou a um equilíbrio na distribuição dos conteúdos da disciplina e deu ênfase, nos objetivos, às práticas de linguagem. É um posicionamento contra o que estava determinado pela tradição, porém, o cotidiano das escolas não segue esse olhar dos contempladores, pois os professores, os que estão na luta, não se posicionam em outro lugar, o do espectador (teoretikós bios). Não lhes é permitido esse lugar, que é possibilitado quando acontece uma constância de políticas públicas que permitem a atualização e a formação continuada dos professores.

O bem que procuramos, a felicidade de nosso ofício, desenha-se, a partir de pesquisas que influenciaram os PCN, e do próprio documento, em torno dos seguintes conteúdos, aqui apresentados de forma sintética:

a) Produção (oralidade e escrita) - falar/fala (dicção, tom, entoação, sonoridade, expressão) em diversos gêneros orais (apropriados pela escola); escrita de textos (narrativos, argumentativos) em diversos gêneros. Leituras produzem textos catalisadores, orais (apresentação, comentários, resumos) e escritos (diários de leitura, resumos, comentários, retextualizações);

b) Recepção (oralidade e escrita) - escuta/ouvir (atenção, compreensão, anotações; exposições do professor, apresentações dos colegas, vídeos); leitura/ler variados gêneros não-literários (informação e crítica; notícias, reportagens, artigos de opinião, textos teóricos) e SOBRETUDO literários (prazer estéti- 
co e crítica; contos, crônicas, romances, poesia, teatro; clássicos, contemporâneos, best-sellers, charges, quadrinhos);

c) Análise linguística - língua (gramática), texto (tipos textuais, coesão, coerência, organização), discurso (interlocução, gêneros do discurso, condições de produção, ideologia), estilo (escolha, contexto, estética), usos da língua (variação linguística, usos cotidianos, uso formal e informal, uso artístico).

São esses três pilares, distribuídos equanimemente, que darão as condições de formação do cidadão quanto aos domínios necessários em sua vida cotidiana e profissional, no que toca à linguagem. São doze anos de ensino básico para a escola conseguir isso. No entanto, faltam as condições para esse resultado, desde a formação, atualização e valorização do professor, até o ambiente escolar mais receptivo, com material apropriado para o ensino dessas competências.

\section{Práticas de estágio e a formação do professor}

Considerando o que foi exposto como o estado da arte de ser professor de Português, hoje, temos o desafio de trabalhar na formação desse professor no Curso de Letras. As licenciaturas em geral receberam uma herança dos cursos superiores voltados para a formação de bachareis, com objetivos de formação em ciência da área e erudição. Gatti (2010), após pesquisar a legislação, as características sócio-educacionais dos educandos, os currículos e as ementas dos cursos de formação de professores, conclui que "é necessária uma verdadeira revolução nas estruturas institucionais formativas e nos currículos de formação". Essa ciência precisa voltar-se para sua "função social própria à escolarização - ensinar às novas gerações o conhecimento acumulado e consolidar valores e práticas coerentes com nossa vida civil." Não são esses propósitos que os cursos de licenciatura estão contemplando, conforme pesquisas de 2008 e 2009 (GATTI, 2010).

Um olhar sobre os projetos de Licenciatura pode enxergar movimentos mais recentes, para superar os diagnósticos anteriores, de preocupação um pouco maior na formação do ofício de professor de Português. Um desses passos é o aumento da carga horária de estágio. Tal fato, porém, torna-se um paliativo, pois, como professores desses alunos no final da sua formação profissional, verificamos que os estudos feitos nas disciplinas do curso voltam-se para a área específica de conhecimento de Letras, sem levar em conta as demandas próprias da escola básica. Dessa forma, o estágio fica com excesso de responsabilidade quanto ao objetivo precípuo da licenciatura, o de formar o profissional para atuar no seu ofício. Confirmamos, assim, a preocupação da pesquisadora: 


\begin{abstract}
A formação de professores profissionais para a educação básica tem que partir de seu campo de prática e agregar a este os conhecimentos necessários selecionados como valorosos, em seus fundamentos e com as mediações didáticas necessárias, sobretudo por se tratar de formação para o trabalho educacional com crianças e adolescentes (GATTI, 2010, p.1375).
\end{abstract}

No campo da prática, o licenciando encontra professores regentes da escolacampo que, seguidores fiéis do livro didático, fazem um percurso do ensino tradicional quanto ao conceito da disciplina, sem levar em conta o meio-termo proposto pelos PCN.

Para registrar as análises dos alunos estagiários nas escolas-campo, selecionamos os diários de observação do contexto escolar e de semirregência, um gênero advindo da necessidade de avaliar o cotidiano pedagógico. Tal gênero constitui-se entre o público e o privado, pois as críticas são subjetivas, pessoais, mas serão lidas pelo professor de estágio. Não são aceitos quaisquer registros diários; uma descrição semelhante à ata é refutada para ceder lugar à crítica. As armas dos alunos são o caderno e o lápis, materiais que, silenciosamente, discretamente, berram, denunciam sinais de sucateamento da escola pública. Tais instrumentos concretos funcionariam como ameaças provenientes de um locus discursivamente construído por práticas reflexivas, a universidade, com procedimentos de operacionalização crítica dos conteúdos? Neste ano de 2013, temos uma amostra dessas dificuldades e das procuras de solução que intentamos. Focalizaremos a formação de professores no âmbito da relação entre os estagiários e os professores regentes das escolas-campo de duas cidades: regiões centrais de Goiânia e Inhumas.

Ainda que estagiários e professores regentes da escola-campo não se conheçam, empiricamente, há uma série de fatores que interseccionam suas relações históricas, comuns a ambos. A função básica da escola, que é ensinar, por parte dos professores, e aprender, por parte dos alunos, configura papéis sociais dados por uma ordem do discurso, que é "um conjunto de enunciados na medida em que se apoiem na mesma formação discursiva [...]" (FOUCAULT, 2005, p. 20).

Uma série de enunciados circula a respeito do professor, o que possibilita a formação discursiva sobre o ofício. Há uma imagem romântica, atribuída a seu dom inato de ensinar, que supera, inclusive, empecilhos cotidianos intransponíveis, como baixa remuneração, falta de disciplina dos alunos, cobrança dos pais, da coordenação da escola, sobrecarga de trabalho doméstico - em função do excesso de alunos e de atividades curriculares -, cansaços físico e psicológico. O paradoxo instaura-se exatamente nessa idealização do professor que tudo aguenta e, ao mesmo tempo, esgota-se: 


\begin{abstract}
A professora $\mathrm{S}$, após o término da aula, conversou um pouco conosco sobre como é sobrecarregado o trabalho em uma escola integral. Segundo ela, muitas exigências devem ser cumpridas e isso desgasta o professor (De um dos diários de semirregência registrado numa escola-campo de Goiânia).
\end{abstract}

A estagiária seleciona lexias como "sobrecarregado", "muitas exigências" e "desgasta" para definir sua percepção da leitura que a professora da escola-campo tece a respeito da profissão de professora. O jogo de imagens sobre a tarefa árdua da professora "coincide" com o arquivo de outros enunciados efetivamente ditos a respeito do ofício docente.

Veremos, a seguir, como a memória interna da professora regente regulamenta a ação de interditar a presença das alunas estagiárias durante as aulas de "estudo dirigido":

Em seguida, ela nos levou para a sala da professora T de inglês, com quem ela monitora aulas de "estudo dirigido". A professora "pediu" (indiretamente) para que nos retirássemos da sala. Ela não quis que assistíssemos à aula. Nos sentimos envergonhadas com a situação, mas saímos. Ficamos na sala dos professores (Continuação do diário citado acima).

A atitude de intimidação da professora da escola-campo perante a presença das alunas estagiárias revela uma performance singular, concernente à rede discursiva concretizada por enunciados que denigrem a formação discursiva da educação pública: sem investimento, sucateada, estagnada na tradição pedagógica. O impedimento de ingresso das alunas estagiárias (elas trabalhavam em dupla) na sala de aula demonstra o atravessamento do discurso do medo, um poder capilarizado, não hierárquico, capaz de provocar desconforto no professor regente da escola-campo, autoridade máxima na condução pedagógica.

Em contrapartida, as alunas estagiárias leem a arbitrariedade da professora regente como a instituição de um poder que as torna subalternas, impedidas de exercer a atividade exigida pelo currículo universitário. Ao se considerarem inferiores, dirigemse à sala dos professores e se sentem "envergonhadas" por terem causado desconforto à professora regente, sem questionarem a legitimidade da voz de comando recebida, causada, por nosso viés de leitura, pela suposta ameaça da presença da universidade, espaço discursivamente engendrado pela reflexão contínua.

A regularidade de enunciados que explicita o impedimento da presença de alunos estagiários na sala de aula do professor regente da escola-campo pode ser verificada também no excerto de diário a seguir: 
Finalizando as aulas de Semirregência, assistiríamos aula no X, porém a professora $\mathrm{M}$ nos pediu para corrigir mais atividades avaliativas. Fomos então para a biblioteca para fazermos essas correções. A prova era igual as anteriores. Dezenove questões cada uma com valor de 5,3. (...) Depois de assim ter feito entregamos as atividades à professora. Como se nota não tivemos a oportunidade de observar a aula em si. Ficamos apenas presas nessas correções. (Diário de semirregência registrado numa escola-campo de Inhumas).

Notamos, mais uma vez, uma ordem do discurso que acumula poderes complexos. Para Rabinow e Rose (abr.2006, p.29), o conceito de biopoder inclui "modos de subjetivação, através dos quais os indivíduos são levados a atuar sobre si próprios, sob certas formas de autoridade, em relação a discursos de verdade, por meio de práticas do self". Há discursos de verdade que demarcam historicamente os papéis sociais do professor regente, já estabelecido e reconhecido pela instituição escolar como autoridade que pode e deve promover ações, como orientar posturas de seus alunos. A presença dos alunos estagiários nas aulas ministradas por ele também orienta uma prática do self, por meio de discursos historicamente possibilitados a respeito da função-sujeito assumida por um professor regente.

O professor regente da escola-campo possui o poder de assinar os documentos comprobatórios das atividades de regência dos alunos estagiários e, por isso, exerce uma voz de autoridade que desmantela o legítimo papel da atividade de estágio: aprendizagem e diagnóstico norteador das práticas iniciais da carreira no magistério. Corrigir avaliações não permite aos estagiários o contato com a rotina do exercício docente, como a sequência didática, os planos de aula, a disciplina do corpo discente, a metodologia de ensino-aprendizagem, o controle do tempo para cada atividade...

Seriam os licenciandos capazes de avaliar uma aula ruim? Seriam também eles resultados de uma prática docente frágil, deficiente, repleta de lacunas, de ausência ou pouca crítica, quem sabe reflexo do legado cultural que se perpetua na tradição pedagógica? Nesse espelho de leituras, nossa perspectiva concentra-se na alienação dos professores regentes, que, apesar de instituírem poderes, contraditoriamente o fazem para a autopreservação, para a intimidade pouco acessada da sala de aula não emergir. Parece deplorável o limite da sala de aula circunscrita aos recônditos da materialidade das quatro paredes, um segredo vergonhoso que não pode explodir.

Verificamos poderes disseminados na relação entre estagiárias e professoras regentes das escolas-campo. Porém, o poder das estagiárias visitantes, em alguns casos, 
com apenas a experiência das aulas de estágio, é reconhecido pela professora regente da escola-campo, que se sente vigiada e, possivelmente, punida pela torre de marfim: a universidade que se revela inalcançável, um lugar de qualificação continuada. Talvez a imagem da professora regente seja sustentada pela suposta atualização de metodologias e conteúdos apre(e)ndidos pelas professoras estagiárias. Sob a ameaça de julgamentos e avaliações negativas, devido à falta de estímulo e despreparo das aulas ofertadas aos alunos, a professora é vítima do processo de sucateamento das escolas públicas, evidenciado pelo discurso sobre a educação pública, ainda que o sistema escolar almeje obliterá-lo.

\section{Novas atenções}

Perante o difícil acerto entre professor de estágio, estagiário e professor da escola-campo, foi feito um projeto de intervenção. Negociamos com a coordenação e os professores da escola a realização de um "Projeto de leitura de narrativas", a ser realizado em curtas cinco aulas. O professor de estágio elaborou o Projeto, procurando dar ênfase à prática de leitura, com suporte na teoria da narrativa, relacionando língua, texto e discurso. Após a experiência, embora tenham lamentado a falta de autonomia, os estagiários apontaram alguns ganhos, como os seguintes:

- Ficou evidente para mim o quanto a leitura é um instrumento útil e necessário para o resgate de uma boa aprendizagem, levando o aluno a perceber o quanto a escola é um ambiente agradável e significativo.

- A boa preparação de um plano de aula se mostrou fundamental para o curso tranquilo de uma aula, visto que sem material e conteúdo organizados logo os alunos dispersam-se e o professor fica falando "sozinho" para os alunos.

- Resolvi continuar o projeto de leitura por meio de e-mails em que eu seleciono textos e faço perguntas acerca da leitura. Espero que esse projeto contribua com minha formação como professora, bem como com a formação deles como alunos leitores.

Essas descobertas (a leitura como instrumento de aprendizagem, planejar a aula com zelo) e procuras (um projeto de leitura conduzida via e-mail) confirmam o valor do bem que temos nas mãos com o ofício de dar aulas de Portu- 
guês. A leitura é a máquina que puxa os demais vagões, sem nos esquecermos dos "esforços no sentido de adotar o meio-termo; e há certo padrão determinando o meio-termo, que dizemos situar-se entre o excesso e a falta e ser conforme a razão" conforme Aristóteles (1996). Já tivemos excesso de aulas sobre a norma culta, falta de aula sobre produção de textos, falta de leitura de livros - está na boa hora de ler e produzir e, equilibradamente, trazer para essas práticas, tanto de leitura quanto de escrita, a análise linguística, que agrega as teorias da língua, do texto e do discurso.

\section{Referências}

ARISTÓTELES. Ética a Nicômano. São Paulo: Nova Cultural, 1996.

BRASIL. Parâmetros Curriculares Nacionais $3^{\circ}$ e $4^{\circ}$ ciclos: língua portuguesa. Brasília: MEC/SEF, 1998.

BRASIL. Orientações Curriculares para o Ensino Médio. Brasília: MEC/SEB, 2006.

FOUCAULT, M. A arqueologia do saber. Trad. de Luiz Felipe Baeta Neves. 7. ed. Rio de Janeiro: Forense Universitária, 2005.

GATTI, B. A. Formação de professores no Brasil: características e problemas. Educação e Sociedade, Campinas, v. 31, n. 113, p. 1355-1379, out.-dez. 2010.

RAZZINI, M. O espelho da nação: a Antologia Nacional e o ensino de português e de literatura (1838-1971). Tese de doutorado. Campinas: Unicamp, 2001.

RABINOW, P; ROSE, N. O conceito de biopoder hoje. Abr. de 2006. Disponível em: $<$ http://periodicos.ufpb.br/ojs/index.php/politicaetrabalho/article/view/6600/4156>. Acesso em: 20 jun. 2013.

SOARES, M. Português na escola: história de uma disciplina curricular. In: BAGNO, M. (org.) Linguística da norma. São Paulo: Loyola, 2002. p. 155-177.

Recebido em: 18 abril 2016

Aceito em: 25 abril 2016 